\title{
Mechanism of Water Infiltration and Defiltration through ZSM-5 Zeolite: Heating and Sodium Chloride Concentration Effect
}

\author{
Yueting Sun, ${ }^{1}$ Jun Xu, ${ }^{1,2}$ Yibing Li, ${ }^{1}$ Xiaoqing Xu, ${ }^{1}$ Cheng Liu, ${ }^{3}$ and Xi Chen ${ }^{2,4,5}$ \\ ${ }^{1}$ State Key Laboratory of Automotive Safety and Energy, Tsinghua University, Beijing 100084, China \\ ${ }^{2}$ Department of Earth and Environmental Engineering, Columbia University, New York, NY 10027, USA \\ ${ }^{3}$ Academy of Armored Force Engineering, Beijing 100072, China \\ ${ }^{4}$ Department of Civil and Environmental Engineering, Hanyang University, Seoul 133-791, Republic of Korea \\ ${ }^{5}$ International Center for Applied Mechanics, SV Lab, School of Aerospace, Xi'an Jiaotong University, Xian 710049, China \\ Correspondence should be addressed to Yueting Sun; syt06@mails.tsinghua.edu.cn and Jun Xu; jx2155@columbia.edu
}

Received 3 September 2013; Accepted 23 October 2013

Academic Editor: Félix Zamora

Copyright (C) 2013 Yueting Sun et al. This is an open access article distributed under the Creative Commons Attribution License, which permits unrestricted use, distribution, and reproduction in any medium, provided the original work is properly cited.

\begin{abstract}
Hydrophobic nanoporous material and wetting liquid together comprise a system with promising energy related applications. The mechanism of the interaction between liquid and solid phase is not fully explored. In this paper, based on the quasistatic compression experiments on investigating the mechanical behavior of ZSM-5 zeolite/ $\mathrm{NaCl}$ solution system, the effects of two key parameters, that is, the pretreatment temperature of ZSM-5 zeolite and $\mathrm{NaCl}$ concentration, are parametrically and quantitatively investigated based on Laplace-Washburn equation. Results show that both pretreatment temperature and $\mathrm{NaCl}$ concentration raise the infiltration pressure and $\mathrm{NaCl}$ can also promote defiltration. The advancing contact and receding contact angle of zeolite$\mathrm{NaCl}$-air system increase with both pretreatment temperature and $\mathrm{NaCl}$ concentration, and the contact angle hysteresis decreases with $\mathrm{NaCl}$ concentration. Results may provide fundamental explanation to the nanoconfined liquid behavior and liquid-solid interaction, thus, to smartly control the mechanical properties of the liquid spring and bumpers for energy dissipation function.
\end{abstract}

\section{Introduction}

Heterogeneous systems containing nanoporous material and liquid may lead to many interesting and promising applications [1], thanks to their highly developed and ultralarge surface [2]. In particular, the energy related applications now receive more and more attention, such as molecular spring [3], shock absorber or damper [4], among others. In essence, the energy absorption/mitigation ability is mainly realized by the basic idea that spreading liquid molecules on the nonwetting nanopores may need a certain value of pressure, that is, the capillary pressure [1]. During the external force driven liquid intrusion into the nanopores, the bulk liquid transforms into molecule group and soon a large surface is developed with large amount of excessive interfacial energy. In the unloading process, the liquid molecules may either completely or partially or not defiltrate at all $[4,5]$, depending on the wetting properties of the liquid and solid phase. This proposed energy conversion mechanism prepares nanoporous materials to be a promising energy dissipation/conversion system with 1-2 higher order of magnitude than traditional materials [6].

The interaction between liquid and solid, as well as the liquid molecule motion in a nanoconfined environment, dominates the infiltration and defiltration process to influence the energy mitigation related behaviors. Therefore, a quantitative explanation to the liquid molecule infiltration and defiltration should be clarified in terms of various system parametric controls, which still remains blank in the current available literatures $[7,8]$. In this paper, water and a type of hydrophobic zeolite, ZSM-5, are chosen to build up a heterogeneous mixture system. A series of parametric quasistatic compression tests are conducted by various preheating temperatures and $\mathrm{NaCl}$ concentrations since these two important 


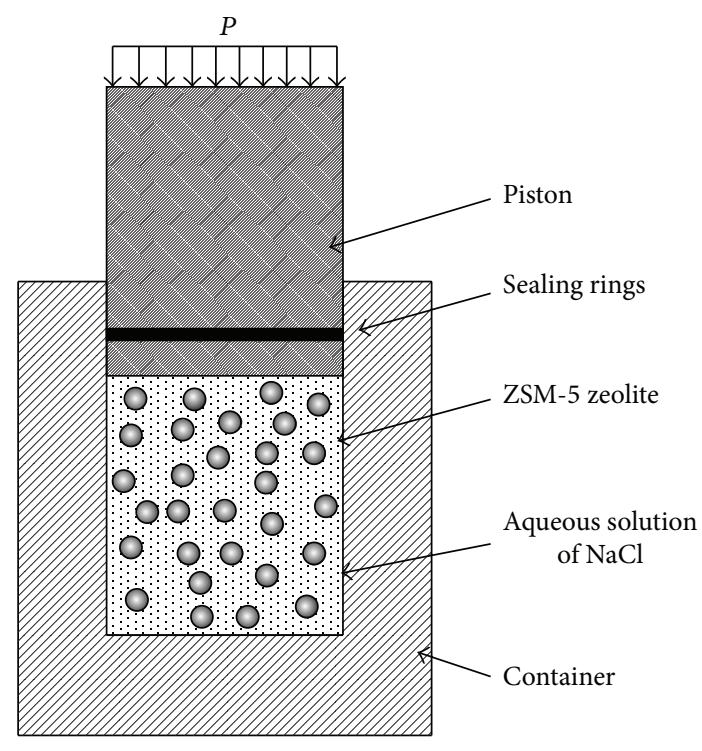

FIGURE 1: Schematic of experimental setup.

TABLE 1: Summarization of physical parameters of ZSM-5.

\begin{tabular}{lcccc}
\hline $\begin{array}{l}\text { Pretreatment } \\
\text { temperature }\left({ }^{\circ} \mathrm{C}\right)\end{array}$ & $\begin{array}{c}\text { Particle size } \\
(\mu \mathrm{m})\end{array}$ & $\begin{array}{c}\mathrm{BET} \\
\left(\mathrm{m}^{2} \mathrm{~g}^{-1}\right)\end{array}$ & $\begin{array}{c}\text { Pore volume } \\
\left(\mathrm{cm}^{3} \mathrm{~g}^{-1}\right)\end{array}$ & $\begin{array}{c}\text { Pore size } \\
(\mathrm{nm})\end{array}$ \\
\hline 600 & 5.450 & 399.0 & 0.1823 & 0.4523 \\
800 & 6.012 & 395.1 & 0.1768 & 0.4523 \\
1000 & 6.069 & 364.6 & 0.1600 & 0.4523 \\
1100 & 6.634 & 334.6 & 0.1559 & 0.4523 \\
\hline
\end{tabular}

factors may have impact on the hydrophobicity of the ZSM5 framework and the liquid surface tension. Infiltration and defiltration are quantified by the threshold pressures, $P_{\text {in }}$ and $P_{\mathrm{de}}$, as well as the contact angles. In addition, observed hysteresis phenomena are discussed to further elucidate the energy mitigation related mechanisms.

\section{Materials and Methods}

The experimental materials in this letter is ZSM-5 zeolite (Zeolite Socony Mobil-five, $\left|\mathrm{Na}_{n}^{+}\left(\mathrm{H}_{2} \mathrm{O}\right)_{16}\right|\left[\mathrm{Al}_{n} \mathrm{Si}_{96-n} \mathrm{O}_{192}\right]$, $n<27$ ) [9], with its physical parameters listed in Table 1 using MasterSizer 2000 particle size analyzer and Quantachrome Autosorb-iQ-MP gas sorption analyzer. ZSM-5 belongs to the zeolyst mobile-five-I (MFI) framework style, characterised by a linear channel and a zigzag channel intersected. The silica-to-alumina ratio of ZSM-5 used here is 300 . Various pretreatment temperatures $\left(600-1100^{\circ} \mathrm{C}\right)$ are adopted for 3 hours and cool down in the air.

Figure 1 schematically shows the experimental setups with a container, piston, and sealing rings. The container is a 316 stainless steel chamber with the diameter of $42 \mathrm{~mm}$ to hold the mixture of ZSM-5 zeolite and $\mathrm{NaCl}$ solution sealed by precisely fit sealing rings. Based on the CSS-2220 MTS experiment platform, the piston is forced to move downward at a loading rate of $5 \mathrm{~mm} / \mathrm{min}$. Once the system pressure reaches $125 \mathrm{MPa}$, the unloading process starts. The friction force between the sealing rings and the piston proves to be rather steady and lower than $5 \mathrm{kN}$, which is trivial compared to the compressive loading. The mass ratio of ZSM-5 zeolite to water is $3: 5$, with $36 \mathrm{~g}$ ZSM-5 zeolite in each test. A precompression of $10 \mathrm{MPa}$ is conducted before each test to produce robust testing data. The pressure holding ability of the chamber has been verified in [10].

\section{Results and Discussion}

3.1. A Typical Sorption Isotherm. Figure 2(a) is a typical sorption isotherm $(P-\Delta V)$ curve using ZSM-5 zeolite pretreated at $1100^{\circ} \mathrm{C}$ with no $\mathrm{NaCl}$ added. The infiltration of water molecules does not start until the applied pressure reaches the threshold $P_{\text {in }}$. The infiltration plateau starts at $P_{\text {in }}$ and ends at $P_{\text {max }}$, with a slope $S_{\text {pla }} \cdot P_{\text {in }}$ and $P_{\max }$ are taken here as the points with a gradient equivalent to $1.5 S_{\mathrm{pla}}$. Similarly, the defiltration of water molecules starts at $P_{\text {de }}$ and ends at $P_{\text {end }}$. Due to the hydrophobicity property of the inwall of nanoproes within ZSM-5 zeolite, water molecules are completely extruded from nanopores, evidenced by the fact that the unloading curve ends at the original starting point.

Figure 2(b) is a simplified ideal isotherm which excludes minor factors, for example, the elastic deformation of water (such that an inclined straight line is simplified as a vertical straight line). Critical parameters, that is, infiltration pressure $P_{\text {in }}$, defiltration pressure $P_{\mathrm{de}}$, advancing capillary pressure $P_{\mathrm{a}}$, receding capillary pressure $P_{\mathrm{r}}$, pressure when infiltration ends $P_{\text {max }}$, pressure hysteresis $\Delta P_{\text {hys }}=P_{\text {max }}-P_{\text {de }}=P_{\mathrm{a}}-P_{\mathrm{r}}$, pressure span $\Delta P_{\text {pla }}$, and volume span $\Delta V_{\text {pla }}$ of the plateau, with $\Delta P_{\text {pla }}=$ $\Delta V_{\mathrm{pla}} \cdot S_{\mathrm{pla}}$, are clearly indicated and defined in Figure 2(b). All these parameters will be explained and analysed in following sections.

3.2. Parametric Test Results. Figures 3(a) and 3(b) depict the influence of pretreatment temperature $T\left(600^{\circ} \mathrm{C}, 800^{\circ} \mathrm{C}\right.$, $1000^{\circ} \mathrm{C}$, and $1100^{\circ} \mathrm{C}$ ) and $\mathrm{NaCl}$ concentration $C_{\mathrm{NaCl}}(0,0.5,1$, 1.5 , and $2 \mathrm{~mol} \mathrm{~kg}_{\text {water }}^{-1}$, that is, moles of salt $/ \mathrm{kg}$ of water) on the sorption isotherm curves, respectively. No change is observed on the global shape of the curves (especially between loading and the corresponding unloading curves at the same experiment conditions), and in order to avoid confusion, only the unloading curves for $600^{\circ} \mathrm{C}$ and $0 \mathrm{~mol} \mathrm{~kg}_{\text {water }}^{-1}$ are shown in Figure 3, in dotted lines. In general, the influence of $T$ mainly lies in $P_{\text {in }}$ and $S_{\text {pla }}$, while $C_{\mathrm{NaCl}}$ mainly impacts $P_{\text {in }}$ and overall stiffness of the mixture; that is, more $\mathrm{NaCl}$ results in smaller deformable volume of the mixture, with larger slope in the pressure rising stage in the beginning of compression. In the following sections, the results will be discussed in detail.

3.2.1. Effect on Infiltration Pressure $P_{\text {in }}$. According to LaplaceWashburn equation, $P_{\text {in }}=P_{\mathrm{a}}=(k / r) \gamma\left|\cos \theta_{\mathrm{a}}\right| ; P_{\mathrm{r}}=$ $(k / r) \gamma\left|\cos \theta_{\mathrm{r}}\right|$, where $k$ is the pore shape factor which is equal to 2 for approximate cylindrical pore for ZSM-5 framework; $r$ is the pore radius; $\gamma$ is the surface tension of the liquid; and $\theta_{\mathrm{a}}$ and $\theta_{\mathrm{r}}$ are advancing contact angle during infiltration and receding contact angle during defiltration, respectively. $P_{\mathrm{a}}$ and $P_{\mathrm{r}}$ can be determined by Laplace-Washburn equation due 


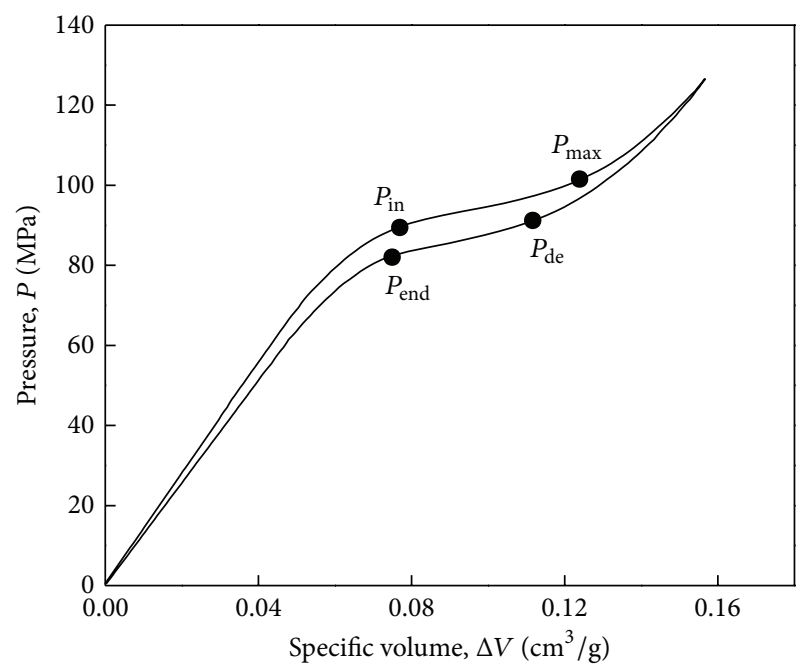

(a)

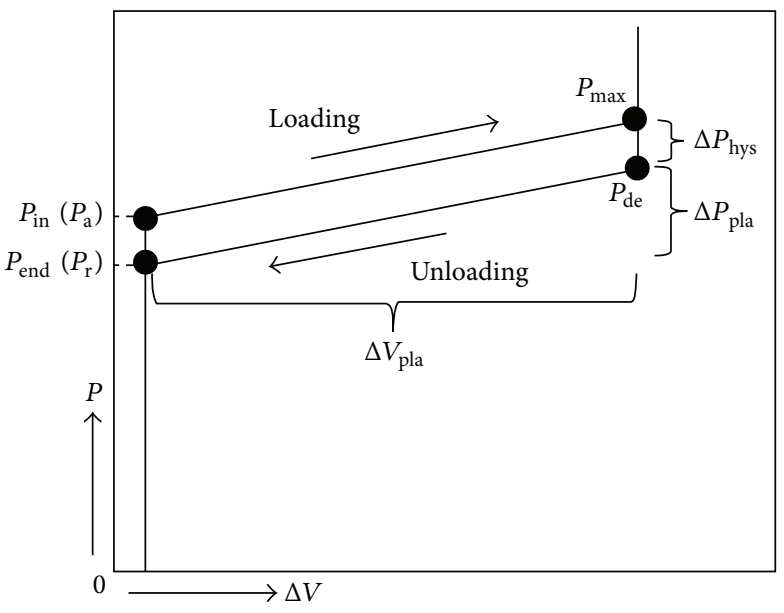

(b)

FIgURE 2: (a) A typical sorption isotherm $(P-\Delta V)$ curve under quasistatic compression test, with pretreatment temperature of $1100^{\circ} \mathrm{C}$ and no $\mathrm{NaCl}$ added; (b) an ideal isotherm.

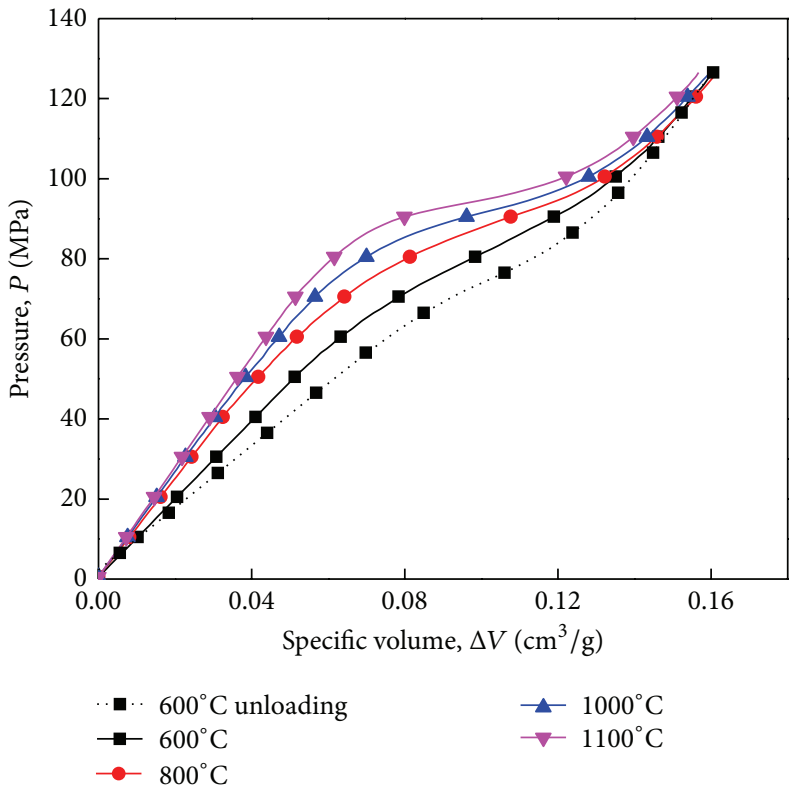

(a)

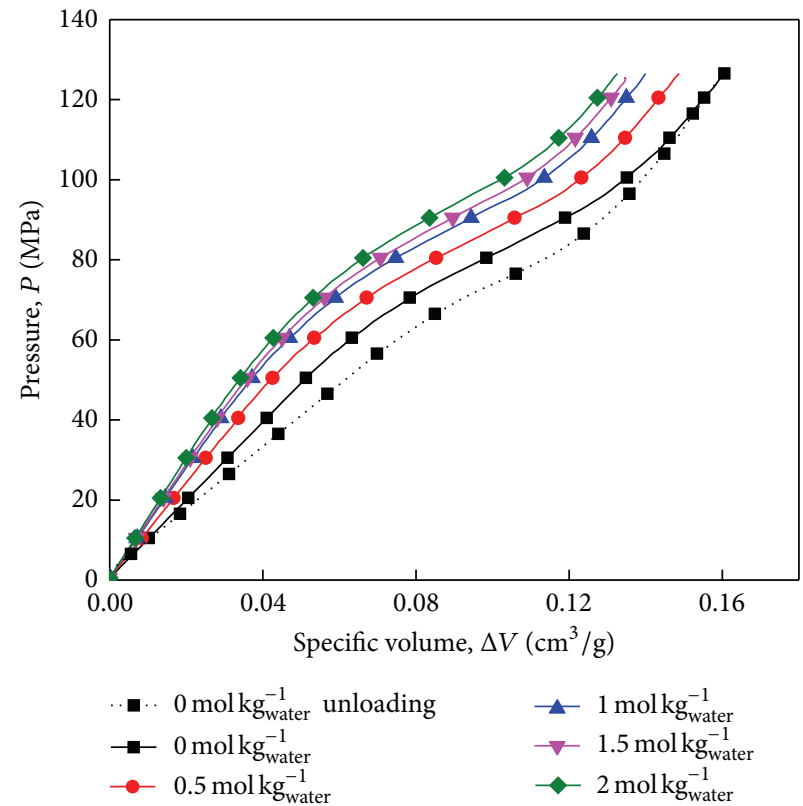

(b)

Figure 3: (a) $P-\Delta V$ curves under quasistatic compression with no $\mathrm{NaCl}$ added and ZSM-5 after pretreatment at $600^{\circ} \mathrm{C}, 800^{\circ} \mathrm{C}, 1000^{\circ} \mathrm{C}$, and $1100^{\circ} \mathrm{C}$, respectively. (The unloading curves for $800^{\circ} \mathrm{C}, 1000^{\circ} \mathrm{C}$, and $1100^{\circ} \mathrm{C}$ are omitted.) (b) $P-\Delta V$ curves under quasistatic compression with

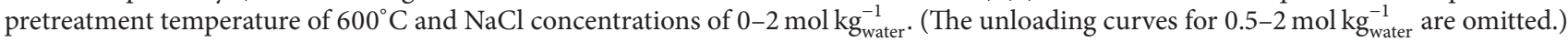

to the quasistatic loading condition [11], and the hysteresis between $\theta_{\mathrm{a}}$ and $\theta_{\mathrm{r}}$ is considered to explain $\Delta P_{\text {hys }}$ which will be analyzed in detail shortly $[12,13]$.

Figure 4(a) shows $P_{\text {in }}$ as a function of $C_{\mathrm{NaCl}}$ at different $T$ s. It is observed that when $T$ is increased from $600^{\circ} \mathrm{C}$ to $1100^{\circ} \mathrm{C}, P_{\text {in }}$ increases by $20 \sim 25 \mathrm{MPa}$. The dealumination of the ZSM-5 framework under high temperature should be a major responsible reason [10]. The dealumination phenomenon can be further demonstrated by (magic angle spinning nuclear magnetic resonance) Al MAS NMR tests shown in Figure 4(b). Two resonances at $50 \mathrm{ppm}$ and $0 \mathrm{ppm}$ indicate the tetrahedrally coordinated framework $\mathrm{Al}$ and octahedrally coordinated nonframework $\mathrm{Al}$, respectively. The intensity of the signal at $0 \mathrm{ppm}$ increases with $T$, indicating the dealumination due to the breaking of $\mathrm{Al}-\mathrm{O}$ bond whose energy is lower than that of $\mathrm{Si}-\mathrm{O}$. The dealumination enhances the hydrophobicity of ZSM-5 framework, which results in weaker adherence of water molecules from the solid phase. Thus, the 


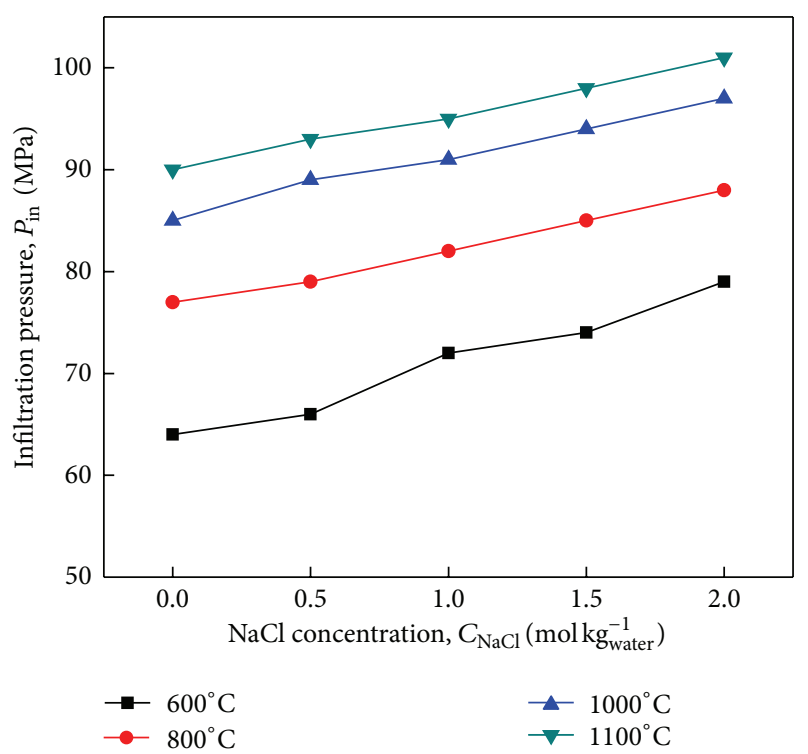

(a)

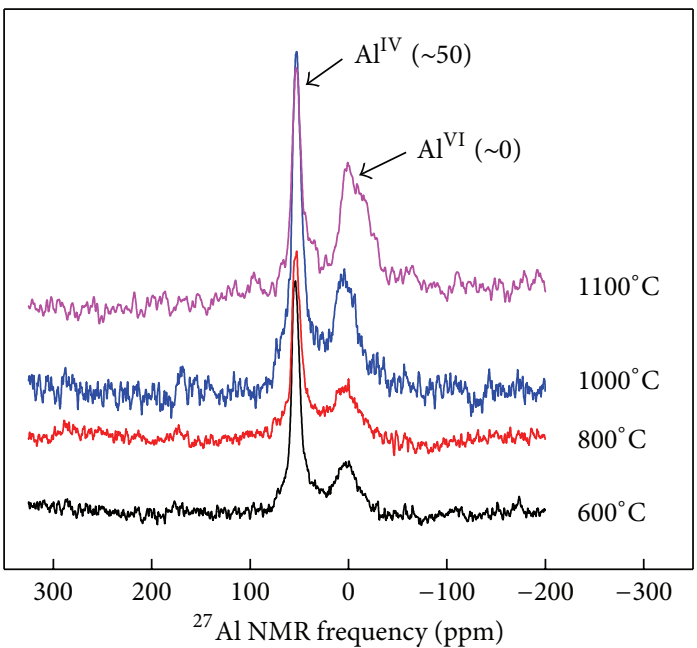

(b)

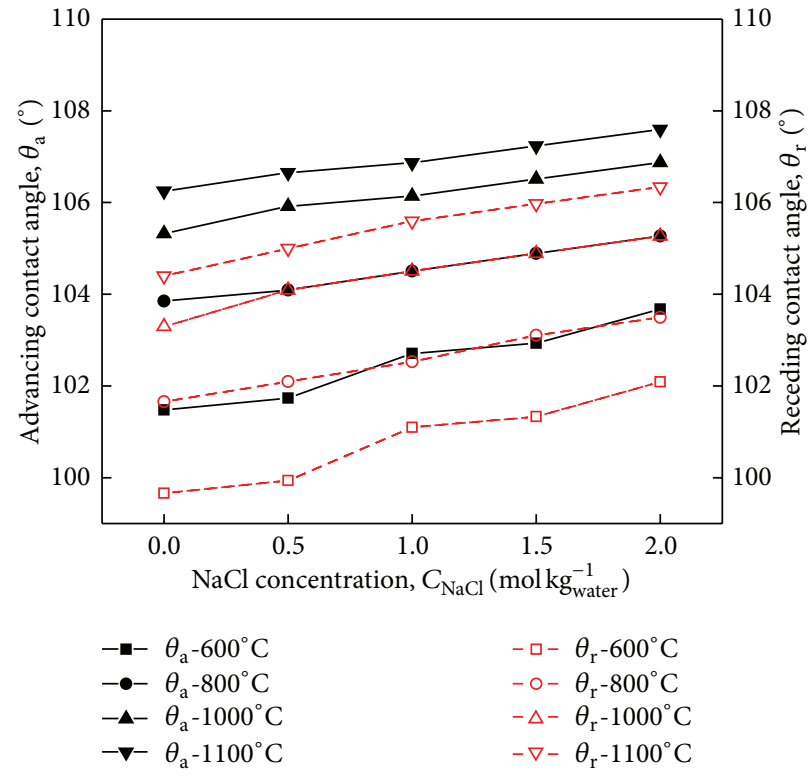

(c)

Figure 4: (a) $P_{\text {in }}$ as a function of $C_{\mathrm{NaCl}}$ at pretreatment temperature of $600^{\circ} \mathrm{C}, 800^{\circ} \mathrm{C}, 1000^{\circ} \mathrm{C}$, and $1100^{\circ} \mathrm{C}$, respectively; (b) Al MAS NMR spectroscopy for ZSM-5 after pretreatment at $600^{\circ} \mathrm{C}-1100^{\circ} \mathrm{C}$; (c) $\theta_{\mathrm{a}}$ and $\theta_{\mathrm{r}}$ as functions of $C_{\mathrm{NaCl}}$ at pretreatment temperature of $600^{\circ} \mathrm{C}, 800^{\circ} \mathrm{C}$, $1000^{\circ} \mathrm{C}$, and $1100^{\circ} \mathrm{C}$, respectively.

contact angle grows higher with $T$. Naturally, according to the above-mentioned Laplace-Washburn equation, $P_{\text {in }}$ increases. Note that other than heat treatment, some kinds of surface treatment can be also employed to change the degree of hydrophobicity, especially for those intrinsically hydrophilic $[14,15]$.

In the meantime, Figure 4(a) also shows that as $C_{\mathrm{NaCl}}$ is increased from 0 to $2 \mathrm{~mol} \mathrm{~kg}_{\mathrm{w} a t e r}^{-1}, P_{\text {in }}$ increases by $10 \sim 15 \mathrm{MPa}$. It has been presented in the open literatures that the surface tension grows higher with the increasing $\mathrm{NaCl}$ concentration
$[16,17]$. This effect is due to the fact that $\mathrm{Na}^{+}$is a structuremaking ion that can strengthen the hydrogen bonds between water molecules by compacting water molecules around themselves and orienting their hydrogen towards neighboring water molecules $[18,19]$. Thus, the enhancing of $\gamma$ may be treated as an explanation for the effect of $C_{\mathrm{NaCl}}$ on $P_{\text {in }}$. Further, a closer quantitative observation reveals that the advancing contact angle $\theta_{\mathrm{a}}$ actually plays the most important role.

In order to provide a deeper investigation, the contact angles $\theta_{\mathrm{a}}$ and $\theta_{\mathrm{r}}$ in various combinations of $T$ and $C_{\mathrm{NaCl}}$ 


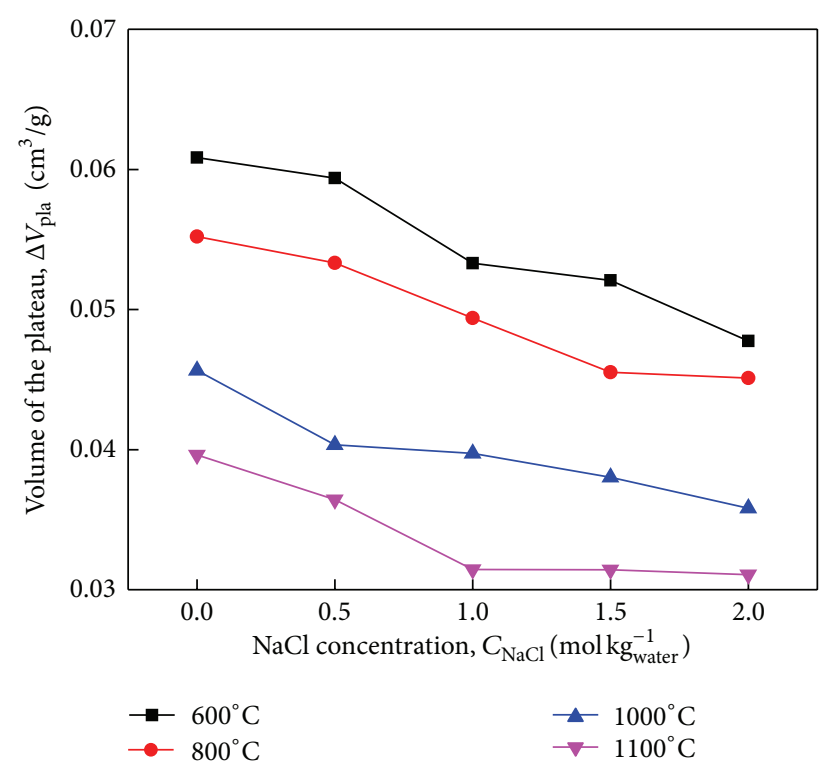

(a)

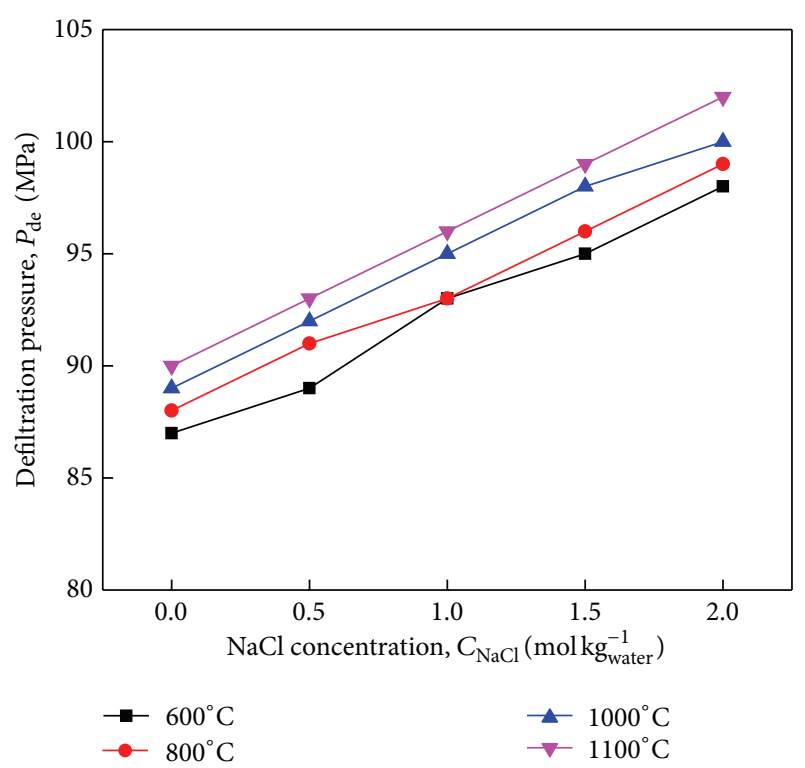

(b)

FIGURE 5: (a) $\Delta V_{\text {pla }}$ as a function of $C_{\mathrm{NaCl}}$ at pretreatment temperature of $600^{\circ} \mathrm{C}, 800^{\circ} \mathrm{C}, 1000^{\circ} \mathrm{C}$, and $1100^{\circ} \mathrm{C}$, respectively; (b) $P_{\mathrm{de}}$ as a function of $C_{\mathrm{NaCl}}$ at pretreatment temperature of $600^{\circ} \mathrm{C}, 800^{\circ} \mathrm{C}, 1000^{\circ} \mathrm{C}$, and $1100^{\circ} \mathrm{C}$, respectively.

are calculated by Laplace-Washburn equation and plotted in Figure 4(c), in which $r=0.4523 \mathrm{~nm}$ (Table 1) and $k=2$; the data of $\gamma$ are extracted from [16]. $\theta_{\mathrm{a}}$ and $\theta_{\mathrm{r}}$ increases with both $T$ and $C_{\mathrm{NaCl}}$. Further, it can be calculated that $\theta_{\mathrm{a}}$ contributes to an $8 \sim 19 \%$ increase in $P_{\text {in }}$ at various pretreatment temperatures as $C_{\mathrm{NaCl}}$ is increased from 0 to $2 \mathrm{~mol} \mathrm{~kg}_{\text {water }}^{-1}$, while $\gamma$ can merely contribute to a $4 \%$ increase in $P_{\text {in. }}$. Thus, the contact angle is the major contributor for the increase in $P_{\text {in }}$.

The reason why $\mathrm{NaCl}$ raises the contact angles needs to be clarified. The effect of $\mathrm{NaCl}$ on contact angle can be easily understood qualitatively. The contact angle is produced by the equilibrium between the relative force of the liquid, solid, and vapor molecular interaction. The structure-making effect of $\mathrm{Na}^{+}$results in a stronger internal attractive force in bulk water; thus, intermolecular bond between water molecule and the solid framework becomes weak, indicated by a high contact angle. Conversely, where the internal force in water phase is low or the force from solid phase is strong, the water molecules tend to spread out on the surface, leading to a small contact angle. For the hydrophobic surfaces of ZSM5 framework after high temperature pretreatment, the gap between the force from the liquid and that from the solid is already quite sharp, thus a further increase on the liquid side can contribute to a limited variation on the contact angle. Figure 4 (c) shows that $2 \mathrm{~mol} \mathrm{~kg}_{\text {water }}^{-1}$ contributes to an increase of no more than $2.5^{\circ}$ in contact angle, which is in line with the finding of Daub et al. [20] and Sghaier et al. [21]. The present work takes $\mathrm{NaCl}$, a commonly used salt as a research object; however, changes in the salt type may induce significant changes in interaction between liquid, solid, and vapor phase, and thus impact the infiltration and defiltration characteristics of water molecules, which will be one of the topics for our future research.

3.2.2. Effect on Defiltration Pressure $P_{d e}$. From Figure 2(b), it is straightforward to come to the equation $P_{\mathrm{de}}=P_{\mathrm{r}}+\Delta P_{\text {pla }}=$ $(k / r) \gamma\left|\cos \theta_{\mathrm{r}}\right|+\Delta V_{\text {pla }} \cdot S_{\text {pla }}$. Thus, $P_{\text {de }}$ is comprehensively impacted by several parameters, including $\gamma, \theta_{\mathrm{r}}, \Delta V_{\text {pla }}$, and $S_{\text {pla }}$.

Figure 5(a) shows that $\Delta V_{\text {pla }}$ goes down with increasing $C_{\mathrm{NaCl}}$, mainly because $\mathrm{Na}^{+}$and $\mathrm{Cl}^{-}$will occupy part of the room for water molecules inside the nanopores. The ionic radii of $\mathrm{Na}^{+}$and $\mathrm{Cl}^{-}$are $0.095 \mathrm{~nm}$ and $0.181 \mathrm{~nm}$, respectively [22], which is comparable to the pore size of ZSM-5. Meanwhile, $\Delta V_{\text {pla }}$ also decreases with $T$ since heating process may produce certain areas inside the channel too hydrophobic and inaccessible for water molecules, and meanwhile a slight part ( $15 \%)$ of the channel may be damaged by high temperature, which is indicated by the pore volume data in Table 1.

$S_{\text {pla }}$ is dominated by a nominal "energy barrier force" which resists water to flow deep into the nanopores so as to maintain a minimum energy potential of the zeolite framework system from being destroyed by infiltration. This energy barrier force is determined by the wetting properties of solid and liquid phase, as well as the air gas molecules [4, 23]. The pretreatment will greatly alter the wetting properties of the solid framework while the concentration of $\mathrm{NaCl}$ cannot. Therefore, change in $S_{\mathrm{pla}}$ is observed in Figure 3(a) but not in Figure 3(b); that is, $S_{\text {pla }}$ decreases with $T$ and has no correlation with $C_{\mathrm{NaCl}}$.

Figure 5(b) depicts $P_{\mathrm{de}}$ as a function of $\mathrm{C}_{\mathrm{NaCl}}$ at different Ts. As $C_{\mathrm{NaCl}}$ is increased from 0 to $2 \mathrm{~mol} \mathrm{~kg}_{\mathrm{water}}^{-1}, P_{\mathrm{de}}$ increases 


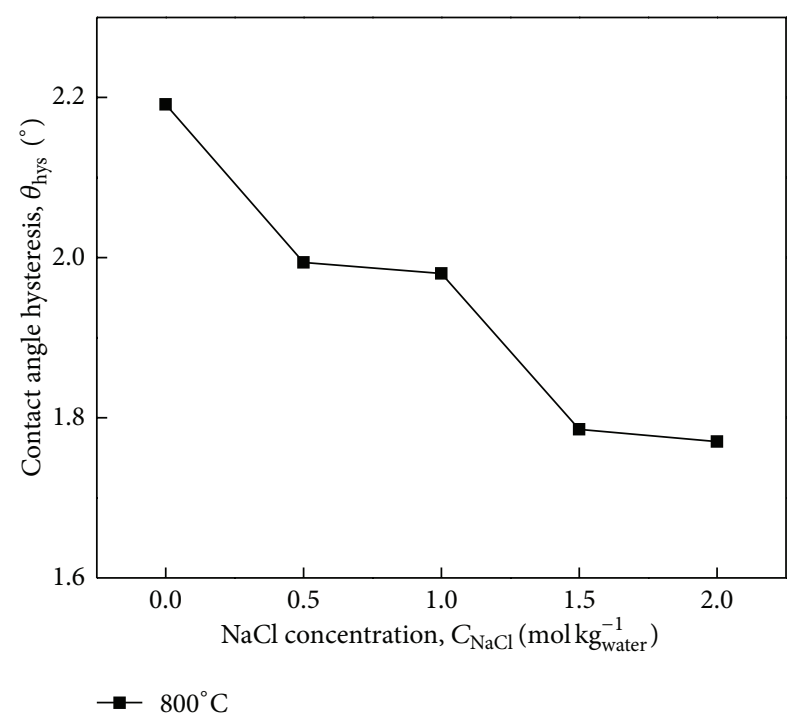

FIgURE 6: $\theta_{\text {hys }}$ as a function of $C_{\mathrm{NaCl}}$ at pretreatment temperature of $600^{\circ} \mathrm{C}, 800^{\circ} \mathrm{C}, 1000^{\circ} \mathrm{C}$, and $1100^{\circ} \mathrm{C}$, respectively.

by $10 \sim 15 \mathrm{MPa}$, which is the same with $P_{\text {in }}$ and indicates that $\mathrm{NaCl}$ has an effect of defiltration promotion. However, no significant correlation can be observed between $P_{\mathrm{de}}$ and $T$ since $\theta_{\mathrm{r}}$ increases with $T$ but both $\Delta V_{\mathrm{pla}}$ and $S_{\mathrm{pla}}$ decrease with $T$.

3.2.3. Effect on Pressure Hysteresis $\Delta P_{h y s}$. Although water molecules flow out of the channels at the end of defiltration completely, a hysteresis can be observed between the loading curve and unloading curve. The hysteresis pressure is defined as $\Delta P_{\text {hys }}=P_{\text {max }}-P_{\text {de }}=P_{\mathrm{a}}-P_{\mathrm{r}}=(k / r) \gamma\left(\left|\cos \theta_{\mathrm{a}}\right|-\left|\cos \theta_{\mathrm{r}}\right|\right)$. In essence, $\Delta P_{\text {hys }}$ dominates the water defiltration behavior. If $\Delta P_{\text {hys }}$ is large, the defiltration will not happen. While $\Delta P_{\text {hys }}$ is small, complete defiltration may occur [5]. Thus, the contact angle hysteresis $\theta_{\text {hys }}=\theta_{\mathrm{a}}-\theta_{\mathrm{r}}$ has a major impact on $\Delta P_{\text {hys }}$, determining the system performance [12-14].

Surface roughness and chemical heterogeneous are two main reasons for contact angle hysteresis $\theta_{\text {hys }}[24,25]$, and other possible causes include liquid sorption on the surface [26] and molecular scale topography [27]. In this case, considering the comprising of both nonpolar oxygen-silicon tetrahedron and polar oxygen-aluminum tetrahedron, the framework of ZSM-5 zeolite is not completely chemically homogeneous [10]. A contact angle is attributed to the energy balance at the solid-liquid-gas contact line [28], which tends to vary locally at the inner wall of the ZSM-5 framework. Thus, during its infiltration or defiltration, water will meet different local energy barriers, which results in contact angle hysteresis. $\theta_{\text {hys }}$ decreases with $C_{\mathrm{NaCl}}$ since under high $\mathrm{NaCl}$ concentration and internal force inside bulk water, the energy barrier at the solid phase can hardly present significant effect. This is indicated by Figure 6 at pretreatment temperature of $800^{\circ} \mathrm{C}$, and the same trend holds for other temperatures. With the definition of $\Delta P_{\text {hys }}$, all these effects on $\theta_{\text {hys }}$ above contribute to the same trend in $\Delta P_{\text {hys }}$, which is a key characteristic during defiltration process.

\section{Conclusion}

A ZSM-5 zeolite/ $\mathrm{NaCl}$ solution system is established to investigate the mechanism of the interaction between wetting liquid and hydrophobic solid at nanoscale. Quasistatic compression experiments are carried out and the effects of two key parameters, that is, the pretreatment temperature of ZSM-5 zeolite and $\mathrm{NaCl}$ concentration, are investigated based on Laplace-Washburn equation, which presents that the system characteristic can be fine-tuned for various situations. Specifically, the infiltration pressure can be raised by increasing pretreatment temperature or adding $\mathrm{NaCl}$; the outflow of water molecules can be accelerated by adding $\mathrm{NaCl}$. Both advancing contact angle and receding contact angle for ZSM5 zeolite- $\mathrm{NaCl}$ solution-air system are determined, indicating that these two increase with both pretreatment temperature and $\mathrm{NaCl}$ concentration. The contact angle hysteresis is also observed, which decreases with $\mathrm{NaCl}$ concentration. This letter can provide explanation to the fundamental behavior of nanoconfined liquid, which may help its application in energy related applications such as liquid spring and bumpers.

\section{Acknowledgments}

The work is supported by International Joint Research Project sponsored by Tsinghua University (20121080050), National Natural Science Foundation of China (11172231 and 11102099), Individual-Research Founding State Key Laboratory of Automotive Safety \& Energy, Tsinghua University (ZZ2011-112), DARPA (W91CRB-11-C-0112), National Science Foundation (CMMI-0643726), Chinese Post-Doctor Foundation, Changjiang Scholar Program from Ministry of Education of China, and World Class University Program through the National Research Foundation of Korea (R322008-000-20042-0).

\section{References}

[1] C. Bréchignac, P. Houdy, and M. Lahmani, Nanomaterials and Nanochemistry, Springer, Berlin, Germany, 2007.

[2] W. J. Roth, P. Nachtigall, R. E. Morris et al., "A family of zeolites with controlled pore size prepared using a top-down method," Nature Chemistry, vol. 5, pp. 628-633, 2013.

[3] Y. Qiao, V. K. Punyamurtula, A. Han, X. Kong, and F. B. Surani, "Temperature dependence of working pressure of a nanoporous liquid spring," Applied Physics Letters, vol. 89, no. 25, Article ID 251905, 2006.

[4] C. V. Suciu, T. Iwatsubo, and S. Deki, "Investigation of a colloidal damper," Journal of Colloid and Interface Science, vol. 259, no. 1, pp. 62-80, 2003.

[5] V. Eroshenko, R.-C. Regis, M. Soulard, and J. Patarin, "Energetics: a new field of applications for hydrophobic zeolites," Journal of the American Chemical Society, vol. 123, no. 33, pp. 8129-8130, 2001. 
[6] B. Xu, Y. Qiao, T. Park, M. Tak, Q. Zhou, and X. Chen, "A conceptual thermal actuation system driven by interface tension of nanofluids," Energy and Environmental Science, vol. 4, no. 9, pp. 3632-3639, 2011.

[7] A. Han and Y. Qiao, "Pressure-induced infiltration of aqueous solutions of multiple promoters in a nanoporous silica," Journal of the American Chemical Society, vol. 128, no. 32, pp. 1034810349, 2006.

[8] X. Kong and Y. Qiao, "Improvement of recoverability of a nanoporous energy absorption system by using chemical admixture," Applied Physics Letters, vol. 86, no. 15, Article ID 151919, pp. 1-3, 2005.

[9] Database of Zeolite Structure, International Zeolite Association, June 2013, http://izasc.ethz.ch/fmi/xsl/IZA-SC/ftc_tm.xsl? $-\mathrm{db}=$ Atlas_main\&-lay=tm\&STC=MFI\&-find.

[10] Y. T. Sun, J. Xu, Y. B. Li et al., "Experimental study on energy dissipation characteristics of ZSM-5 zeolite/water system," Advanced Engineering Materials, vol. 15, no. 8, pp. 740746, 2013.

[11] E. W. Washburn, "The dynamics of capillary flow," Physical Review, vol. 17, no. 3, pp. 273-283, 1921.

[12] L. Coiffard and V. Eroshenko, "Temperature effect on water intrusion/expulsion in grafted silica gels," Journal of Colloid and Interface Science, vol. 300, no. 1, pp. 304-309, 2006.

[13] O. V. Ievtushenko, V. A. Eroshenko, Y. G. Grosu, J. M. Nedelec, and J. P. E. Grolier, "Evolution of the energetic characteristics of \{silicalite-1 plus water\} repulsive clathrates in a wide temperature range," Physical Chemistry Chemical Physics, vol. 15, no. 12, pp. 4451-4457, 2013.

[14] A. Han and Y. Qiao, "Controlling infiltration pressure of a nanoporous silica gel via surface treatment," Chemistry Letters, vol. 36, no. 7, pp. 882-883, 2007.

[15] N. Y. Chen, "Hydrophobic properties of zeolites," Journal of Physical Chemistry, vol. 80, no. 1, pp. 60-64, 1976.

[16] N. L. Jarvis and M. A. Scheiman, "Surface potentials of aqueous electrolyte solutions," Journal of Physical Chemistry, vol. 72, no. 1, pp. 74-78, 1968.

[17] P. K. Weissenborn and R. J. Pugh, "Surface tension of aqueous solutions of electrolytes: relationship with ion hydration, oxygen solubility, and bubble coalescence," Journal of Colloid and Interface Science, vol. 184, no. 2, pp. 550-563, 1996.

[18] P. Leroy, A. Lassin, M. Azaroual, and L. André, "Predicting the surface tension of aqueous $1: 1$ electrolyte solutions at high salinity," Geochimica et Cosmochimica Acta, vol. 74, no. 19, pp. 5427-5442, 2010.

[19] B. Hribar, N. T. Southall, V. Vlachy, and K. A. Dill, "How ions affect the structure of water," Journal of the American Chemical Society, vol. 124, no. 41, pp. 12302-12311, 2002.

[20] C. D. Daub, D. Bratko, and A. Luzar, "Electric control of wetting by salty nanodrops: molecular dynamics simulations," Journal of Physical Chemistry C, vol. 115, no. 45, pp. 22393-22399, 2011.

[21] N. Sghaier, M. Prat, and S. Ben Nasrallah, "On the influence of sodium chloride concentration on equilibrium contact angle," Chemical Engineering Journal, vol. 122, no. 1-2, pp. 47-53, 2006.

[22] L. Pauling, "The sizes of ions and the structure of ionic crystals," Journal of the American Chemical Society, vol. 49, no. 3, pp. 765790, 1927.

[23] C. V. Suciu, T. Iwatsubo, K. Yaguchi, and M. Ikenaga, "Novel and global approach of the complex and interconnected phenomena related to the contact line movement past a solid surface from hydrophobized silica gel," Journal of Colloid and Interface Science, vol. 283, no. 1, pp. 196-214, 2005.
[24] J. D. Eick, R. J. Good, and A. W. Neumann, "Thermodynamics of contact angles. II. Rough solid surfaces," Journal of Colloid And Interface Science, vol. 53, no. 2, pp. 235-238, 1975.

[25] S. Brandon and A. Marmur, "Simulation of contact angle hysteresis on chemically heterogeneous surfaces," Journal of Colloid and Interface Science, vol. 183, no. 2, pp. 351-355, 1996.

[26] C. N. C. Lam, R. Wu, D. Li, M. L. Hair, and A. W. Neumann, "Study of the advancing and receding contact angles: liquid sorption as a cause of contact angle hysteresis," Advances in Colloid and Interface Science, vol. 96, no. 1-3, pp. 169-191, 2002.

[27] A. Y. Fadeev and T. J. McCarthy, "Trialkylsilane monolayers covalently attached to silicon surfaces: wettability studies indicating that molecular topography contributes to contact angle hysteresis," Langmuir, vol. 15, no. 11, pp. 3759-3766, 1999.

[28] P. G. Degennes, "Wetting: statics and dynamics," Reviews of Modern Physics, vol. 57, no. 3, pp. 827-863, 1985. 

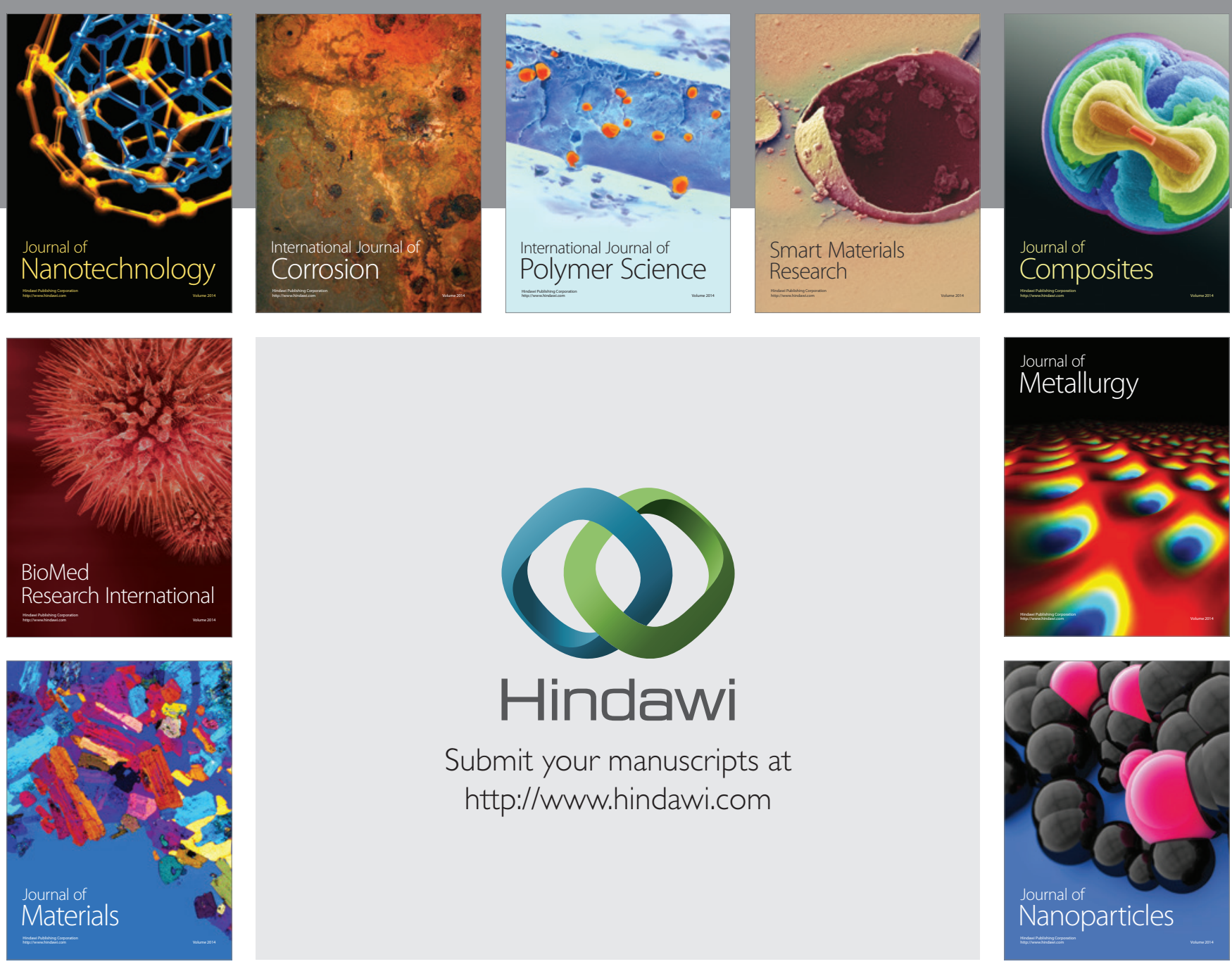

Submit your manuscripts at http://www.hindawi.com
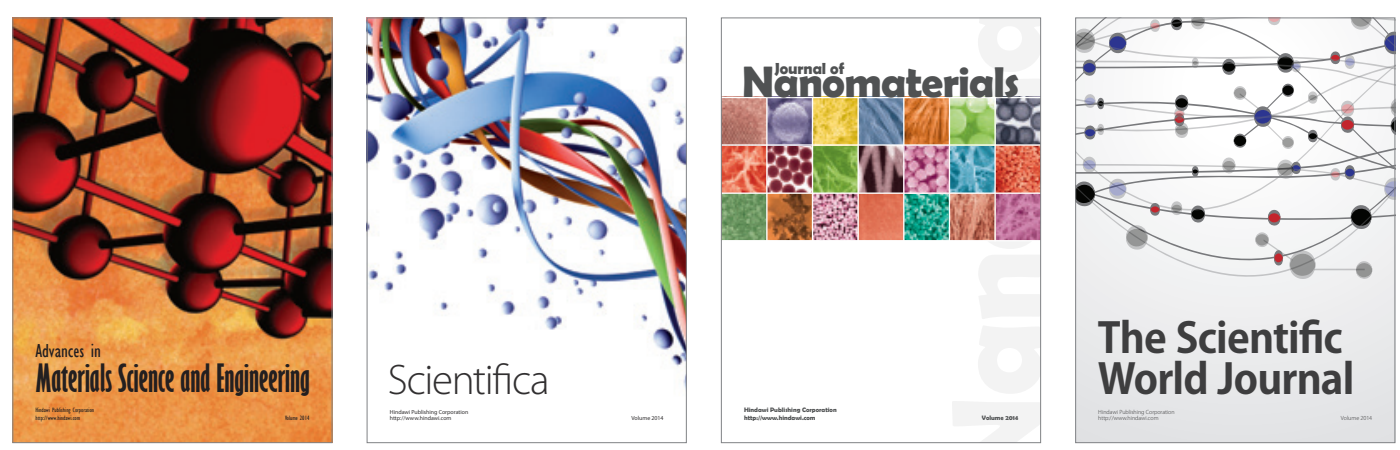

\section{The Scientific World Journal}
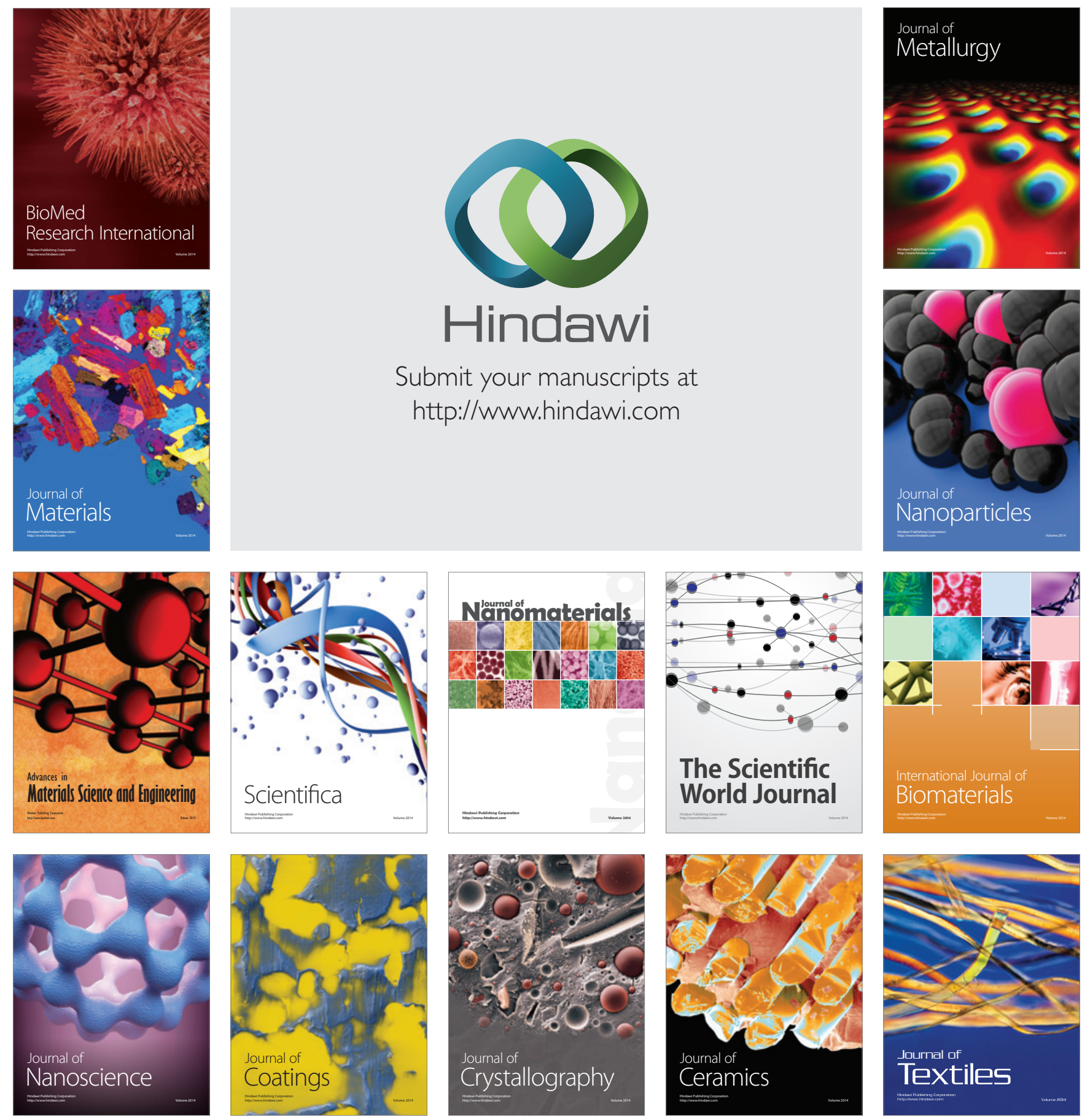